\title{
Una hermenéutica más de cara al debate sobre la valoración moral del aborto*
}

\section{\Santiago Roldán García**}

ONE MORE HERMENEUTIC IN THE DEBATE ON THE MORAL ASSESSMENT OF ABORTION
UMA HERMENÊUTICA MAIS DIRETA AO DEBATE SOBRE A AVALIAÇÃO MORAL DO ABORTO

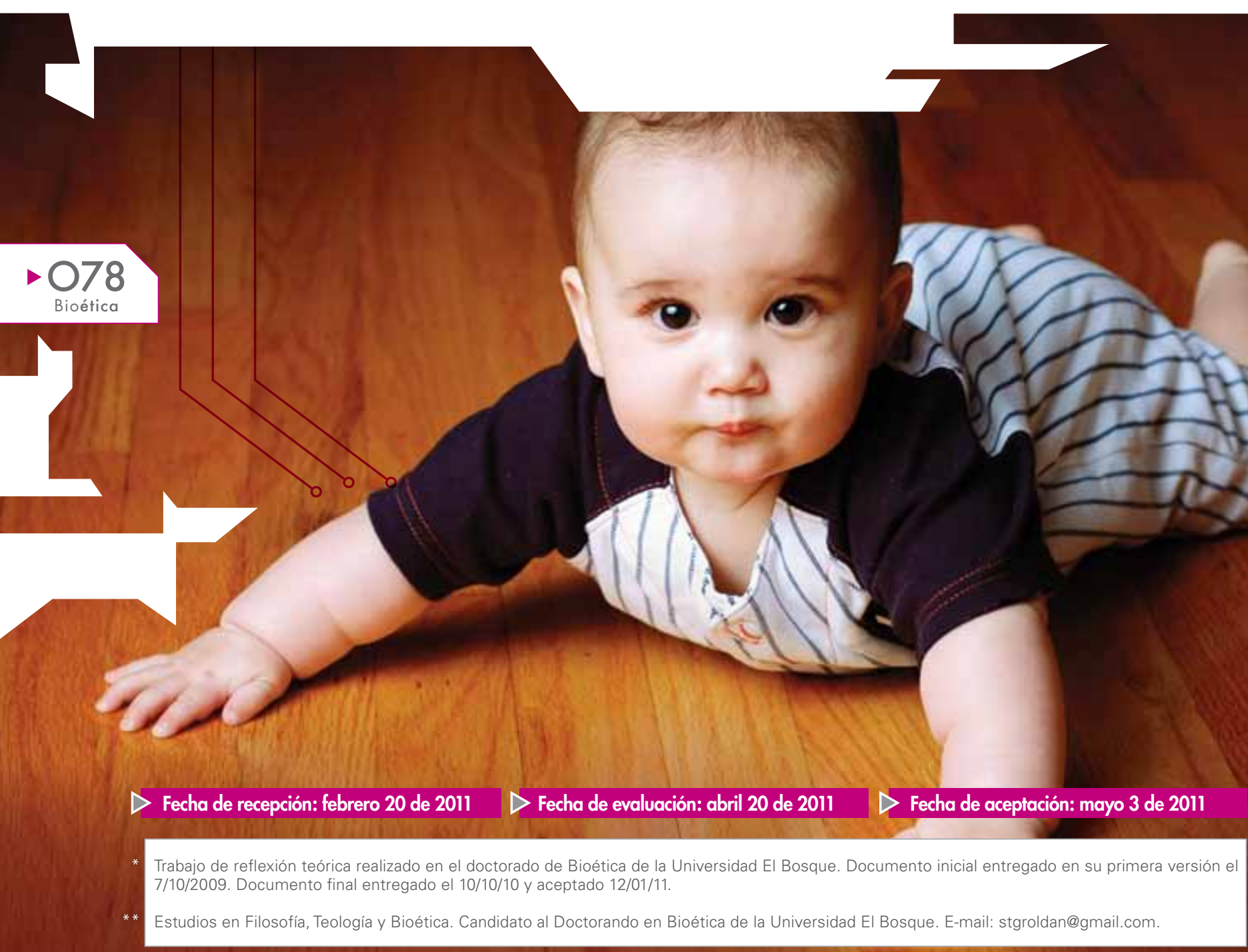


UNA HERMENÉUTICA MÁS DE CARA AL DEBATE SOBRE LA VALORACIÓN MORAL DEL ABORTO / Santiago Roldán García

\section{RESUMEN}

Desde una nueva lectura hermenéutica, se comprende desde la bioética que el tema sobre la inquietud moralmente valorativa frente a la terminación de un embarazo, no se encuentra enmarcada solamente en una perspectiva académica y ad intra de la misma. Se propone la inclusión y el análisis de otros factores y tipos de agentes implicados en el debate sobre la hominización y sus respectivas consecuencias valorativas en cuanto a lo ético y moral que, asumiendo la comprensión de la génesis del pensamiento, la tendencia de evolución del mismo y su innegable extensión, se proyecten a comprender muchos de los hechos, tanto empíricos como racionales con los que cuenta el ser humano para acercarse a una toma de decisiones al respecto.

\section{Palabras Clave}

Aborto, valoración, autonomía, conciencia intencional, comportamiento del ser humano.

\section{ABSTRACT}

From a new hermeneutic reading from bioethics is understood that the issue of moral concern valuation from termination of a pregnancy, is framed not only in an academic perspective in the same ad intra. We propose the inclusion and analysis of other factors and types of stakeholders in the debate on the humanization and their valuation implications as to what ethics and morals, which assume understanding of the genesis of thinking, the same trend of changes and their undeniable expansion, are projected to comprise many of the empirical and rational facts are there in humans to approach a decision about it.

\section{Key Words}

Abortion, assessment, autonomy, awareness intentional human behavior.

\section{RESUMO}

Com uma nova leitura hermenêutica, a partir da bioética se compreende que o tema da inquietação quanto à avaliação moral da interrupção de uma gravidez não se encontra enquadrado apenas sob uma perspectiva acadêmica e ad intra da mesma. Propõe-se a inclusão e a análise de outros fatores e tipos de agentes implicados no debate sobre a hominização e suas respectivas consequências avaliativas quanto ao caráter ético e moral que, assumindo-se a compreensão da gênese do pensamento, da tendência de evolução do mesmo e sua inegável extensão, sejam projetados para se compreender muitos dos fatos, tanto empíricos quanto racionais, que o ser humano dispõe para chegar a uma tomada de decisões a respeito.

\section{Palavras-chave}

Aborto, avaliação, autonomia, consciência intencional, comportamento do ser humano. 


\section{UN PUNTO DE INICIO}

En una investigación monográfica anterior (Roldan, 2010), me di a la tarea como teólogo católico de indagar y enunciar diversos puntos de vista con respecto al debate sobre la hominización del embrión humano de cara a la valoración moral; de si se podía afirmar que la persona humana existía desde el momento mismo de la fecundación y en dónde cualquier interrupción de un embarazo sería vista como homicidio' osi, por el contrario, la persona humana existía no desde el momento de la fecundación, sino a partir de un momento posterior a ella y que por lo tanto hablar de homicidio en la interrupción del embarazo, sería aplicable sólo después de tal momento.

Observaba con gran interés académico que así fueran biológicos, antropológicos, filosóficos y hasta teológicos, estos argumentos evidenciaban de manera muy clara una disparidad tanto de posturas como de contenidos. Del mismo modo, determinaban de una u otra forma y con características propias, la manera de abordar y valorar el tema tanto de la acción como del comportamiento humano en relación al principio y al final de la vida humana, por parte de sus ponentes y seguidores.

En ese orden de ideas, anoté que una primera postura, a la cual opté por llamar "postura A", sostenía la existencia de la persona humana desde el momento mismo de la fecundación del óvulo por parte del espermatozoide y en donde cabría afirmarse: que cualquier interrupción de un embarazo sería vista como homicidio. Así mismo, comenté que a esta postura del pensamiento le pareció lógico sostener que la persona existía ya desde el primer momento de la fecundación y que por tanto, hablar de vida humana desde ese preciso momento se hacía, más que viable, necesario, pues en ello iría el reconocimiento tácito de que esa vida humana, que es el cigoto en donde se encuentra el código genético de la persona humana en forma compleja y que, a partir de dicho código, el proceso gestacional se desarrolla en un proceso continuo sin interrupción y por autogestión. Es ya una persona humana en potencia con todos sus derechos y por tanto, la interrupción provocada del proceso gestacional sería siempre homicidio.

Igualmente, en dicha investigación, evidencié la existencia de otra postura, "postura B", que proponía hablar de la persona humana ya no desde el momento mismo de la fecundación, sino desde un estado posterior a ella: y que por lo tanto hablar de homicidio en la interrupción del embarazo sería aplicable sólo después de tal momento. En esta segunda postura, se reconocía evidentemente el dato científico de que el cigoto contiene su propio código genético específico; pero se contradecía, eso sí, la afirmación genérica según la cual basta la existencia del código genético en el cigoto para que, a partir de dicho código se genere un proceso continuo por autogestión que, de no ser interferido, concluye en lo que se denomina persona humana.

Con lo anterior, después de un gran trabajo académico, al que invito a acercarse con más detenimiento, dicha investigación monográfica concluía que era evidente, teológicamente hablando, el comprender la existencia de una gran incongruencia magisterial con respecto a la valoración moral del comportamiento del ser humano en relación a este tema. Y que, por lo tanto, era importante para mí como teólogo motivar al lector a que se diera a la tarea de observar críticamente algunas consideraciones morales pertinentes al respecto:

1. Por un lado, que si bien desde el Magisterio eclesial se condena siempre moralmente el homicidio de una persona inocente e indefensa como asesinato ${ }^{2}$; por el otro lado, y desde la comprensión de un "aborto indirecto", se estaría justificando moralmente dicha acción basados en el postulado aristotélico-tomista en donde se considera que el principio del "doble efecto", según el cual, el efecto malo no pretendido directamente sino en forma indirecta hace lícita moralmente la acción total ${ }^{3}$.

2. Si nos acercamos a la comprensión magisterial de la búsqueda de la absolutización del derecho a la vida, de manera tal que pareciera que siempre que alguien quita la vida a otro ser humano inevitablemente incurre siempre en una acción moralmente mala e imputable como tal; paradójicamente, no se comprendería en ese mismo hilo argumentativo la licitud de la acción del aborto indirecto en la que de todas maneras, se está quitando la vida a un ser humano. Pasaría lo mismo con la aceptación magisterial de que en determinados casos quitarle la vida a otro ser humano puede ser una acción moralmente justificada, no consentida como mala y, por tanto, no censurable. Tal es el caso de la legítima defensa, de la guerra "justa" o de la pena de muerte.

Cabe anotar precísamente en esta consideración, que el acudir a la proposición de inocencia o indefensión, si 
fuera el caso, simplemente se estaría argumentando desde un análisis de la realidad circunstancial y en un contexto de manejo racional y razonable de los motivos, lo que obviamente señalaría la no absolutez del valor de la vida. En este caso, sería más adecuado afirmar, consiguientemente, que el valor de la vida es un bien fundamental pero no absoluto.

3. Desde una argumentación deontológica, el pronunciamiento eclesial trata el tema del aborto recurriendo a formulaciones y pronunciamientos, muchos de ellos de carácter absoluto e irrefutable, fundamentado en el: deber directo que tiene todo ser humano de respetar la vida. Igualmente, se expresa la prohibición, también absoluta, de suprimir la vida en gestación. Aunque, no hay que olvidar, que esta pretendida absolutez admite algunas excepciones.

Pero, y desde una argumentación teológico-moral, la utilización de la palabra "directamente" no especifica la moralidad de la acción, como ya se había dicho. Y la característica de inocente e indefensa, tampoco.

4. Según los pronunciamientos mencionados, esta corriente del pensamiento magisterial no duda en condenar dura y moralmente la consecución ${ }^{4}$ del aborto en forma genérica e indiscriminada. Esta forma de proceder no parece la más apropiada, por la sencilla razón de que en esta misma corriente se reconoce la: licitud de algunos abortos. La condenación debería ser mucho más clara, al explicar que se trata únicamente de los abortos no lícitos y moralmente no aceptables.

5. Si bien es cierto que permanentemente en la vida estamos tomando decisiones éticas y opciones entre diversas posibilidades; es aquí, donde se evidencian dos conjeturas: o la conciencia nos muestra racionalmente unos valores y deberes en juego y, entonces, con claridad discernimos el bien que debemos realizar, o nos encontramos en una situación de conflicto de valores o deberes y, resulta supremamente difícil a la conciencia discernir en cuál de las opciones reside el bien que debemos realizar.

Resulta por tanto evidente que un elemento inherente a la conciencia humana es la capacidad para sopesar comparativamente los valores y deberes cuando éstos se hallan presentes en dos opciones posibles que se presentan en conflicto. Es también constitutivo a la conciencia humana el captar, en este proceso comparativo y evaluativo de los valores, en cuál de los dos extremos de la balanza reside una mayor "cantidad" de bienes o de bondades. De manera que, de todas maneras, la conciencia es capaz de discernir el bien mayor frente a otros bienes en conflicto.

Vista la misma realidad en términos negativos, la conciencia es capaz de discernir cuál es el mal menor entre dos males que se seguirían de un determinado comportamiento.

6. Finalmente, y según lo enunciado en el pronunciamiento oficial del Magisterio eclesial ${ }^{5}$, para la Iglesia Católica existen dos posturas diferentes con base teológica y científica sobre si existe o no la persona desde el momento mismo de la fecundación.

Por más que la oficialidad de la iglesia toma postura a favor de la existencia de la persona desde el momento de la fecundación, y en donde cualquier interrupción de un embarazo es vista como homicidio; declara con gran acierto que esta afirmación: no es de "fe definida" y permanece abierta, en cualquier caso, a ulteriores consideraciones.

\section{UN PASO MÁS ALLÁ}

Dada así esta reflexión monográfica, que personalmente continúo considerándola como urgente, necesaria y oportuna para el contexto y la reflexión teológica y académica en Colombia; hoy, desde una nueva oportunidad intelectual orientada desde la Bioética quiero ir más allá de mi propio resultado académico de cara a la reflexión del juicio valorativo del aborto desde sus muchas implicaciones tanto éticas como morales con respecto al comportamiento del ser humano, bien sea a nivel individual o colectivo.

Deseo darme a la tarea de proponer, que si bien dicho cuestionamiento aludía a una inquietud moral del comportamiento vista desde una perspectiva como teólogo católico en donde era importante comprender el tipo de valoración del comportamiento de un individuo como homicida o no, de cara a la terminación de un embarazo; éste mismo cuestionamiento moral no puede quedarse ahí simplemente. Ha de trascendérsele a otras instancias del pensamiento humano y a otras hermenéuticas no solamente a las teológicas, en atención a que muchos de los problemas biológicos, 
antropológicos, éticos, teológicos y jurídicos que se plantean en el inicio de la vida humana han partido, desde mi propio punto de vista, de la premisa de que todos nosotros vivimos en una sociedad diversa y transcultural, y no tanto en una sociedad de código ético único.

Por tanto, se comprende igualmente desde este escrito, que se pueden dar respuestas distintas e incluso opuestas, a estos problemas e interrogantes de cara a la terminación o no de un embarazo y a su juicio valorativo, tanto ético como moral. De modo tal, que así como se busca la comprensión, el entendimiento y el respeto de un tipo de reflexión y argumentación frente a una postura del conocimiento; se apoya la evidente necesidad por comprender, entender y respetar igualmente cualquier otro tipo de argumentación y comprensión en el discurso académico, en beneficio de la propia consideración de validez dentro del debate.

Así, y en un contexto plural y pluralista, siguiendo las palabras de Gilbert Hottois (2004), no debería sorprendernos el que no haya ya una unanimidad a la hora de responder preguntas como cuál es el alcance ético y moral y los límites del derecho a la vida y qué lugar ha de ocupar la autonomía reproductiva de la mujer a la hora de hablar del aborto.

Dicho de este modo, se hace importante considerar en un segundo momento desde este escrito que, si bien la conciencia intencional del sujeto juega un papel preponderante dentro de la toma de decisiones ante dilemas del principio o del final de la vida, desde un ámbito de lo diverso, plural y pluralista, la comprensión moral de la intencionalidad del obrar responsable ha de vislumbrársele mucho más ampliamente a fin de evitar cualquier interpretación solipsista de la moralidad de cara a la situación dilemática de la consecución o no del aborto (Engelhardt, 1995) (a).

Finalmente, y como tercer momento, se hace necesario razonar desde esta misma perspectiva bioética, que dicha inquietud moralmente valorativa e investigativa, no se encuentra enmarcada solamente en una perspectiva académica y ad intra de la misma, en este caso de la teología moral católica; sino que urge un diálogo mucho más abierto e incluyente en donde se proponga la inclusión de otros factores y tipos de agentes implicados en el debate sobre la hominización y sus respectivas consecuencias valorativas en cuanto a lo ético y moral, siendo éstas, por ejemplo, la desigualdad social, 
el desempleo, la pobreza, el repudio, la presión sociocultural, la amenaza de algunos padres, el abandono de los hijos a su libre albedrío, la falta de valores, el afán por vivir, entre otras. (b)

En últimas, a lo que pretendo llegar en este escrito, es a motivar al lector a comprender la idea de que se necesita plantear este diálogo valorativo del aborto y sus múltiples consideraciones tanto éticas como morales de cara al estatuto del embrión humano, al terreno de lo bioético desde una perspectiva de encuentro y diálogo pluralista, intercultural y evolutivo (Engelhardt, 1995), en donde, evitando posturas dogmáticas o indiferentes, nos sentemos a la mesa diversas disciplinas para generar, de manera tolerante e incluyente, una toma de decisiones que redunde en beneficio de la dignidad y la calidad de vida del ser humano.

\section{A) POR EL FORTALECIMIENTO DE UN ACTUAR RESPONSABLE}

En atención a lo anteriormente enunciado, se hace importante para este escrito y desde los presupuestos bioéticos de la Autonomía y la Responsabilidad, el considerar que, si bien la conciencia intencional del sujeto juega un papel preponderante dentro de la toma de decisiones ante situaciones dilemáticas tanto éticas como morales del principio o del final de la vida; desde un ámbito de lo plural y pluralista, ha de vislumbrársele mucho más ampliamente a fin de evitar cualquier interpretación sesgada de la moralidad de cara al dilema de la terminación de un embarazo.

Así, y en palabras del profesor Francesc Torralba Roselló, siguiendo los planteamientos de J. Rawls y Dworkin, se comprende desde una búsqueda por la comprensión de la concientización intencional del sujeto,

Que una persona autónoma no puede aceptar sin una consideración independiente, el juicio de otras sobre qué hacer o qué creer. Puede confiar en el juicio de otras, pero al hacerlo debe estar preparado para adelantar razones independientes a favor de la probable corrección de estos juicios y para sopesar el valor evidente de sus opiniones frente a razones contrarias (Torralba, 1999, pp. 19 - 32).

En ese orden de ideas, si el mundo del hombre y la mujer es un mundo artificial, construido a partir del conocimiento, y si ese conocimiento es una resultante de la integración del sujeto y el objeto en los actos cognitivos que cobran significación para el sujeto a partir de los valores involucrados desde su intencionalidad (Cadena, 2009); entonces, y en continuidad con el profesor Carlos Delgado, no es posible afirmar para la Bioética una relación cognitiva objetiva que excluya al sujeto y no lo trascienda (Delgado, 2008).

Por lo tanto, antes de entrar a abordar este mundo y este conocimiento, este ser humano, visto inicialmente como un dinamismo abierto que tiene que incidir en el mundo asumiéndolo de manera consciente, ha de apropiarse de la realidad con el fin de que trascendiéndola en la medida en que sea capaz de tomar decisiones responsables, propenda por la comprensión de sus propios actos de libertad y de autonomía.

En lectura del filósofo Hans Jonás, este movimiento del saber humano que en forma de ciencia natural ha puesto a nuestra disposición esas fuerzas cuya utilización tiene ahora que ser regulada por normas, articula una ética nueva de la responsabilidad que partiendo de una antropología filosófica se adentra en la metafísica de los mismos actos humanos. (Jonas, 1995).

Desde esas mismas palabras se avizora para mí, un nuevo acercamiento al conocimiento, por vía de la comprensión y la asimilación de la realidad, mediante una nueva epistemología que se emplaza en la comprensión de la conciencia intencional del sujeto de cara a la posibilidad del conocimiento y a su subsiguiente aplicabilidad y aprehensión de lo valorativo, lo subjetivo y lo objetivo desde su propia concienciación de su comportamiento y de sus actos delante de una toma de decisiones pertinente.

Si bien es cierto que uno de los elementos esenciales del nuevo saber (refiriéndose a la Bioética) está en relación con el reconocimiento del carácter interno de lo valorativo y lo moral, en el conocimiento científico (Delgado, 2008), de igual forma y con mayor ahínco, pero sin desconocimiento alguno de lo evidente ${ }^{6} \mathrm{y}$ aparente ${ }^{7}$ del objeto, entra en el diálogo bioético objeto-sujeto la certidumbre de una realidad existencial que no podemos desconocer: la concienciación por parte del sujeto de dicha realidad se descubre y re-descubre tanto en el agente cognoscente como en lo cognoscible.

En razón entonces al cuestionamiento sobre una hermenéutica más de cara al debate sobre la interpretación ética y moral del aborto, y bajo el convencimiento bioético de la necesidad de comprender muchos de los 
hechos tanto empíricos como racionales con los que cuenta el ser humano para acercarse al conocimiento y con ello actuar de modo responsable, se recrea nuevamente (citado ya en muchos escritos de mi autoría) y con la ayuda de las ideas del teólogo Bernard Lonergan (1988), algunos de los pasos que posibilitan al ser humano la comprensión de la conciencia intencional y de su actuar responsable, desde la diferenciación de sus cuatro grandes canales. Comienza así la nueva propuesta hermenéutica de cara al debate sobre la valoración moral del comportamiento del ser humano en relación a la terminación de un embarazo:

Inicialmente el primer canal, el sensible, en donde el ser humano, percibiendo sensorialmente lo material logra una extensión de su corporeidad. Llega así, a lo que para Aristóteles va a ser un conocimiento a través de los sentidos puesto que abriéndolos, este ser humano se va adentrando e insertando en el mundo. Al captar los datos inmediatos, va forjándose el cascarón necesario del ser humano.

Pero, y consecuentemente siguiendo a Bernard Lonergan, este ser humano que ha empezado un proceso cognitivo por lo sensible, no pretende quedarse allí. Por lo tanto se hace necesario buscar un estadio en donde, a diferencia de los animales se pregunte por lo que oye, por lo que ve, por lo que palpa... En otras palabras, por lo que siente.

Se busca entonces, un segundo canal el entendimiento, en donde este hombre y esta mujer trascendidos por la pregunta: ¿Qué es eso que percibo? empiezan una dimensión nueva: la mía y la de la realidad. Este paso lleva por tanto al ser humano de un nivel anterior a un nivel superior.
Si este hombre y esta mujer no preguntan, se quedan en el campo de lo sensible. Pero si lo hacen, buscan entender lo que perciben de modo sensorial. Este segundo nivel es netamente humano, ya que el animal no se cuestiona y no le interesa pasar de un nivel físico a otro más trascendente. En última, esa pregunta no se hace con los sentidos, puesto que se trata de un nivel más elevado: "Entiendo mi Yo, y eso me hace inteligente".

En el tercer canal, la experiencia que ha sido entendida, viene precedida por una segunda pregunta acerca del ser de las cosas. Es una de las preguntas más radicales que pretende llevar al individuo a la verificación.

¿Aquello -se pregunta el ser humano- que entiendo, es así como lo entiendo? ¿Es real o es una quimera? A esta operación se le denomina razonamiento.

Con la inteligencia, para Lonergan, se capta la realidad pero no se verifica. Entonces el ser humano debe proceder a verificar la realidad. Eso es la verdad experimental.

Es decir, que el mundo físico pasa al mundo de las esencias y después se racionaliza hasta generar el fruto del tercer canal: el Juicio.

Lo cuestiono, lo pregunto, lo ausculto y me proyecto a un conocimiento verdadero.

Comparándolo con la lógica aristotélica, se pasa de una idea al concepto, de la representación mental a la materialización de la misma. Se continúa con lo más elaborado y racional como lo son, tanto el juicio como el raciocinio, hasta llegar a un conocimiento exacto (dentro lo que se puede llamar exacto en el conocimiento).

Precede ahora una tercera pregunta que hace referencia a si, cuando se llega al ser de las cosas, el ser humano puede llegar a otra actividad como ser humano que le integre.

Una persona autónoma no puede aceptar sin una consideración independiente, el juicio de otras sobre qué hacer o qué creer. Puede confiar en el juicio de otras, pero al hacerlo debe estar preparado para adelantar razones independientes a favor de la probable corrección de estos juicios y para sopesar el valor evidente de sus opiniones frente a razones contrarias. 
Finalmente, la respuesta siendo afirmativa, nos lleva a un cuarto nivel, ya que este hombre y esta mujer se descubren en un primer orden como un ser no simplemente homogéneo (es decir igual adentro que afuera), y en uno segundo, en cuanto a que los entes en sus estratos ónticos pasan de lo menos a lo más. El nivel físico es el menos óntico por estar menos cargado de Ser.

Así, llegamos al nivel del obrar responsable ya que este es la mayor trascendencia a la cual puede acceder el hombre. La bondad se capta cuando se considera la protección intelectual en aras del Sentido.

Se hace por tanto necesario elaborar la pregunta sobre el ¿para qué?.

Viene con ello la pregunta moral sobre lo bueno o lo malo. Es necesario entonces un elemento mucho más calificado que los anteriores: la Conciencia. Ella, puede generar una escala de valores en donde todo lo que se haga, sea sometido a un juicio de valor.

Es aquí donde siguiendo a B. Lonergan, se describe al sujeto en una forma minuciosa en donde éste ha de "hacerse" para "proponerse" trascendentalmente.

Por último, en los canales $1^{\circ}, 2^{\circ}$ y $3^{\circ}$, el ser humano recibe información. Pero es tan sólo en el $4^{\circ}$ canal en donde se apropia y apersona de la realidad de una manera responsable (Concienciación).

Y es así, que dados los anteriores canales dentro de la comprensión bioética de una epistemología de segundo orden, en donde superando una racionalidad clásica y objetiva del conocimiento; se aboga en este escrito, ya no tanto por el objeto en sí del conocimiento sino por el sujeto contextuado que observa junto con sus subsiguientes ópticas y hermenéuticas con respecto a dicha realidad de cara a la comprensión del obrar responsable del sujeto (Delgado, 2008).

Tal es el caso de la valoración del comportamiento de cara a la interrupción de un embarazo, en donde sin llegar a ser absolutistas e indiferentes se necesita la intención primera por comprender y entender no sólo las diversas hermenéuticas que se encuentran y entrelazan en este debate del aborto, sino las argumentaciones y ópticas de cara a la valoración del actuar ante la interrupción o no de un embarazo en donde se está apropiando y apersonando la realidad de una manera responsable.

E igualmente, desde la propuesta de una elaboración sistemática de la conciencia intencional del sujeto como elemento esencial para la concienciación de sus actos, se procura la comprensión por la intencionalidad primigenia del comportamiento como ofrecimiento epistemológico de tercer orden.

Llegados a este punto de comprensión, y en consonancia con las palabras de F. Torralba (1999), podríamos acercarnos a hablar de la construcción de un nuevo tipo de comprensión y de diálogo hermenéutico, frente a la multiplicidad de toma de decisiones, necesario para la comprensión de esta problemática y vadeado desde la propia significación de la Autonomía en cuanto que propende por la significación de "la capacidad de querer algo, de obrar consciente y voluntariamente." Se pretende la construcción del sujeto autónomo y de la comprensión de la autonomía de sus mismas convicciones, acciones y/o omisiones.

\section{B) POR EL FORTALECIMIENTO DE UN DIÁLOGO PLURAL Y PLURALISTA}

Con la intención de relacionar lo dicho anteriormente, en donde, por un lado, se sostenía que este cuestionamiento valorativo sobre el comportamiento del sujeto moral y ético de cara a la terminación de un embarazo y su consecuente debate sobre la hominización del embrión humano, no se hallaba enmarcado en tan sólo una hermenéutica y perspectiva del conocimiento científico y, por el otro, se proponía una comprensión racional de la conciencia intencional del sujeto; se observa en este escrito que urge un diálogo mucho más abierto e incluyente de otro tipo de factores y agentes que invitan a la reflexión bioética a apoyarse en los principios de Autonomía y Responsabilidad, no ya como puntos arquimédicos para resolver todos y cada uno de los problemas que se plantean en la realidad (Torralba, 1999), sino como referentes hermenéuticos transculturales (Roldan, 2010) plurales o pluralistas necesarios para una mejor toma de decisiones ante este tipo de discusión y de debate.

Si bien se ha concluido en diversas investigaciones tanto públicas como privadas en Colombia ${ }^{8}$ que los tópicos a analizar dentro de la discusión y la problemática de la interrupción de un embarazo son muy diversos y multipintos: la situación personal de las mujeres que se han practicado abortos, la reincidencia en el hecho, las condiciones sociales, culturales y demográficas, las circunstancias familiares y coyunturales, los núcleos de 
conflicto y las rutas de decisión, las prácticas oficiales y clandestinas que han surgido con el aborto y sus múltiples reglamentaciones y decretos, ademas de las redes sociales y su papel como ámbitos de control y solidaridad. Hoy desde este escrito, se comprende que ya no se puede desconocer en la discusión pública o privada, el uso irrestricto de la libertad y la autonomía del individuo sin desmedro alguno de la responsabilidad ante el hecho mismo del consentimiento de la terminación de un embarazo.

El debate aquí ya es otro. El otro punto esencial para esta nueva propuesta hermenéutica de cara al debate sobre la hominización del embrión humano, dicho anteriormente, no se emplaza ya en la valoración y la evaluación de los hechos y los actos mismos del sujeto moral, sino en la fundamentación moral de nuestras decisiones morales dado que, y en palabras del doctor Diego Gracia, al no existir actividades en la vida humana libres de valores, urge un entendimiento al cómo justificar nuestras opciones de valor; cómo elegir racionalmente entre lo correcto y lo incorrecto, lo bueno y lo malo (Gracia, 1991).

Se necesita por tanto una re-comprensión de la intencionalidad moral del sujeto que actúa junto con las diversas situaciones atenuantes para la valoración de su propio comportamiento.

Si bien, dicho en otras palabras y apoyado ahora en lo mencionado por Pablo Simón Lorda, "la inteligencia sentiente aprehende las cosas como de suyo reales $y$, por tanto, como formalmente buenas, y a las personas, como un de suyo que además es suyo, y por tanto, como dignas de consideración y respeto, como sujetos morales con realidad de dignidad. Así se genera el marco canónico de la moralidad, el sistema formal de referencia que luego la razón debe dotar de contenido material mediante esbozos morales, mediante propuestas normativas, que siempre serán contingentes, históricas y relativas" (Simón, 2002).

Siendo así, la Autonomía se convierte en un atributo de los hombres y las mujeres contemporáneos, y en núcleo esencial de una antropología de donde nace una determinada visión de la moralidad que hace necesario contemplar su dimensión como principio objetivo de la acción, como ley moral. Desde esta perspectiva, y nuevamente apoyados con Pablo Simón Lorda, podríamos decir con él, que constituye el centro del sistema canónico de referencia, pues la capacidad de los seres racionales para darse a sí mismo leyes universales que guíen su comportamiento empírico, es la clave de la idea de dignidad (Simón, 2002).

Así y tan solo así, es entendido para este escrito que nadie puede imponerle a otro ser humano que actúe, piense $\mathrm{o}$ analice tal situación de determinada manera, pues se estaría vulnerando entre otros, el propio principio de Autonomía y se le estaría negando la posibilidad de edificar y responder a su propio estilo y modo de vivir (Ferrer y Martinez, 2002). Aunque y claro sería, sí se le puede urgir moralmente a que lo haga en atención a una obligación ética sociocultural.

No podemos desconocer por lo tanto, que la Autonomía tiene, como afirma Torralba, dos aspectos: por un lado, la capacidad del hombre de desarrollar, a partir de sí mismo y de su propia comprensión de la realidad una comprensión y una visualización de los propios fines de su vida y de los medios para alcanzarlos. Todo ello, sin condicionamientos externos que vayan en contravía y perjuicio de su propia representación. Y por el otro lado, significa la realización de lo que uno quiere realizar, de acuerdo con las propias fuerzas y los condicionantes sociales y políticos (Torralba, 1999).

Entendiendo de este modo y buscando apoyar una mayor comprensión de la intencionalidad del comportamiento en atención al cuestionamiento sobre ¿qué pesa más en la decisión de abortar?, realizado por la Dra. Lucero Zamudio (1998), se ve que para la población de menores recursos tanto económicos como familiares, son las circunstancias de momento las que adquieren prioridad a la hora de tomar la decisión y decidir su propio comportamiento: son abandonadas por su compañero, se encuentran desempleadas, la familia no las apoya o sencillamente no están preparadas para asumir dicho estado de maternidad.

Y cuando se mira ¿qué ocurre después de tomar la decisión de abortar?, nace un encuentro con mujeres, especialmente las de sectores populares y de menor edad, que se someten arriesgadamente a cualquier procedimiento, aún a los que ponen en peligro su propia vida. Incluso, algo más de una cuarta parte de mujeres que abortaron nunca permitieron que su compañero tuviera conocimiento sobre el embarazo y el aborto, aunque en algunos casos, es decir un tercio de mujeres, particularmente en su primer aborto, se vieron obligadas por su compañero a practicarlo. 
Del mismo modo, existen otras consideraciones que desde la Bioética pienso importante que sean tenidas en cuenta ante la valoración no sólo del comportamiento mismo de cara a la terminación de un embarazo sino ante la propia concienciación del acto mismo de abortar. La primera, una dicotomía entre la normatividad que lo penaliza y el desarrollo tecnológico que pone a disposición métodos y medicamentos de muy bajo riesgo; otra, entre el ejercicio del derecho y la determinación de la ciencia y la técnica sobre la configuración de lo público y lo privado. De ahí que el aborto se vuelva un asunto penalizable por la mediación de un tercero, el que practica el aborto, al convertirlo en asunto público. La tercera, por una parte, entre la limitación cultural con respecto al acceso a una anticoncepción segura y la legislación sobre el aborto, y por otra, el desempleo, la decadencia de los salarios, la discriminación hacia las mujeres en estado de embarazo, la carencia de apoyo a las madres y la presión social hacia las familias de más de tres hijos hasta el punto de señalarlas como socialmente irresponsables. Esta tensión es tal vez la fuente de mayores padecimientos físicos y emocionales que agobian a las mujeres pobres.

Una cuarta tensión se da entre la dinámica de la situación y la capacidad del Estado para hacer efectivas las sanciones que la norma anuncia, lo que genera un mensaje ambíguo. Es también interesante observar que tampoco las personas más allegadas a las mujeres que han experimentado un aborto inducido, son conscientes del carácter delictivo de esta conducta y adoptan así una actitud de indecisión, se mueven entre la duda moral sobre lo que es justo y lo adecuado de la norma y la creencia en la necesidad de control social sobre esta conducta.

La quinta tensión, que muestra este estudio, está entre la opinión pública y la acción privada apareciendo como un asunto de doble moral, dado que ambas posturas se presentan en la conciencia de la gente como dos mundos totalmente aislados. A esta se suma la tensión entre dos instancias de regulación social -el Estado y la Iglesia- que tienden a confundir sus niveles de intervención y muchas veces conscientes o no elaboran obstáculos y crean una situación de estancamiento social en el asunto, debilita su propia capacidad reguladora y asistencial (Zamudio y Rubiano, 1994).
Siguiendo a Bernard Lonergan, este ser humano que ha empezado un proceso cognitivo por lo sensible, no pretende quedarse allí. Por lo tanto se hace necesario buscar un estadio en donde a diferencia de los animales se pregunte por lo que oye, por lo que ve, por lo que palpa... En otras palabras, por lo que siente. 


\section{CONCLUSIONES}

De cara al análisis valorativo del comportamiento del ser humano frente al debate sobre la hominización del embrión humano y a la posibilidad de la terminación de un embarazo, se evidencia la necesidad bioética por acercar al dialogo diversas posturas del conocimiento, que sin pretensiones absolutistas o fundamentalistas para con sus adeptos, apoyen la comprensión y la convivencia de las distintas y aún diferentes variedades conceptuales, hermenéuticas y axiológicas de los individuos que habitan sociedades pluralistas, plurales y transculturales y no tanto, de códigos éticos únicos.

En razón de una novedad bioética a este cuestionamiento valorativo del comportamiento, se hace importante recordar la propuesta metodológica de un nuevo acercamiento endógeno que, asumiendo la comprensión de la génesis del pensamiento, la tendencia de evolución del mismo y su innegable extensión; se proyecte a comprender muchos de los hechos tanto empíricos como racionales con los que cuenta el ser humano para acercarse al conocimiento y a la realidad.

Y con ello, a actuar de modo responsable desde la búsqueda de una fundamentación moral de sus decisiones morales, en razón de que ninguna de sus acciones, se encuentran alejadas del constructo cultural, de una escala de valores que motive al entendimiento y logre así justificar y elegir racionalmente y en conciencia, una acción ante determinadas situaciones dilemáticas.

Se hace importante recordar, desde la sabiduría bioética, que si bien la conciencia intencional del sujeto juega un papel preponderante dentro de cualquier toma de decisiones ante dilemas del principio o del final de la vida, desde un ámbito de lo diverso, plural y pluralista, la comprensión moral de la intencionalidad del obrar responsable ha de vislumbrársele mucho más ampliamente a fin de evitar cualquier interpretación solipsista de la moralidad, de cara a la situación dilemática de la consecución o no del aborto.

Si bien es cierto que desde el respeto por el ejercicio de la autonomía y la conciencia de cualquier sujeto moral, nada ni nadie puede imponerle a otro un análisis, un pensamiento o una actuación ante determinada situación so pena de estar vulnerando sus derechos; lo es también el hecho, de que existe un tipo de responsabilidad individual o colectiva que se emana de la comprensión misma de

\section{Así y tan solo así, es en- tendido para este escrito que nadie puede imponer- le a otro ser humano que actúe, piense o analice tal situación de determinada manera, pues se estaría vulnerando entre otros, el propio principio de Autono- mía y se le estaría negan- do la posibilidad de edifi- car y responder a su propio estilo y modo de vivir.}

la realidad y su repercusión dentro del éthos sociocultural creado y vivido en sociedades pluralista y transculturales.

En el análisis de una integralidad del sujeto moral, este ser humano ha de apropiarse de la realidad en consciencia, con el fin de que trascendiéndola en la medida que sea capaz de tomar decisiones responsables, propenda por la comprensión de sus propios actos en La libertad, Autonomía y Responsabilidad. Un actuar responsable en términos de moralidad, encuentra gran parte de su comprensión, desde la asimilación hermenéutica del acercamiento a la realidad por parte del sujeto moral quien, entendiéndola, la racionaliza de modo tal, que desde la comprensión de su sentido, opta y decide el tipo de actuación con tal fundamentación que exige ser entendida y dialogada.

Tras lo dicho anteriormente, parece necesario concluir que el ser humano, necesita ir creando su vida y proyectarla en forma de sistemas de posibilidades, que han de ser fundamentados y justificados ante sí mismo y ante los demás, en beneficio de una tarea de desciframiento e interpretación moral de la realidad. Así, convirtiendo el proceso moral en un proceso hermenéutico, se propone para el sujeto moral el imperativo de la construcción de 
principios, la formulación de leyes y normas, pero también la ponderación de circunstancias y consecuencias. Ello, en aras de la dignificación misma del comportamiento del ser humano.

En ese orden de ideas, se comprende desde la sabiduría bioética, que ya no se puede desconocer en la discusión pública o privada, el uso irrestricto de la libertad y la autonomía del individuo, sin desmedro alguno de la responsabilidad ante el hecho mismo del consentimiento de la terminación de un embarazo.

\section{NOTAS}

Para este escrito entiéndase homicidio (Del lat. homicid um) como la muerte causada a una persona por otra. Der. Delito consistente en matar a alguien sin que concurran las circunstancias de alevosía, precio o ensañamiento. DICCIONARIO DE LA LENGUA ESPAÑOLA - Vigésima segunda edición. 2009

2 Cf. Véase de igual forma el pronunciamiento magisterial en el Catecismo de la Iglesia Católica No 2270-2275. Para este escrito, entiéndase asesinato (Del ár. ašš š n, adictos al cáñamo indio) como el matar a alguien con premeditación, alevosía, etc. Cf. DICCIONARIO DE LA LENGUA ESPAÑOLA - Vigésima segunda edición. 2009.

3 Este postulado del doble efecto se aplicó a los casos tanto del embarazo ectópico como del de la muerte segura de madre y feto si no se procedía al aborto, observando que si se trataba de aborto "indirecto" era lícito y no denunciable como homicidio de una persona inocente e indefensa, esto es, como asesinato.

4 Entiéndase la acción misma de conseguir o procurar un aborto.

5 Cf. Declaración final del Congreso Internacional organizado por la Academia Pontificia para la Vida sobre "El embrión humano en la fase de la preimplantación" publicado en la Edición italiana del "L'Osservatore Romano" el 23 de marzo de 2006.

6 Entiéndase desde el lat. ev dens, - entis en relación a lo que cierto y patente es y sin duda alguna se evidencia.

7 Del lat. appar re, en referencia a lo que se aparecer

8 Cf. RAMÍREZ, Socorro, "Realidades y Magnitudes del Aborto Inducido: Colombia" Santiago de Chile, FEMPRESS - Agencia de Prensa de la Mujer Latinoamericana, mayo del 2000; AGATON S, Isabel. El aborto: un análisis desde la perspectiva de los Derechos Humanos. Monografía para optar al título de Especialista en Derechos Humanos. P. 64; LEONELLO, Martha Zapata. p. 270-271. En: Universidad Externado de CoIombia, Problemática Religiosa de la Mujer que aborta. p 25; Universidad Externado de Colombia. Problemática Religiosa de la Mujer que Aborta. Encuentro de investigadores sobre aborto inducido en América Latina y el Caribe. 1.994. p 25; Juan Pablo II, Carta encíclica Mater et Magistra. Mayo 15 de 1961, 3: AAS 53, 447; CONGREGACIÓN PARA LA DOCTRINA DE LA FE, Declaración sobre el aborto procurado (18 de Noviembre de 1974), 738. Esta cita es dada directamente por la encíclica Evangelium Vitae. Pág. 133.

\section{REFERENCIAS}

- Abel, S. (1983). Bioética, un nuevo concepto y una nueva responsabilidad. Labor Hospitalaria, España, 17(196):101-111.

- Bedate, A. y Cefalo, R. (1989). The zygote: to be or not to be a person, The Journal of Philosophy and Medicine, 14: 641-645.

- Bedate, A. (1989). Reflexiones sobre cuestiones de vida y muerte: Hacia un paradigma de comprensión del valor ético de la entidad biológica humana en desarrollo, en AA.VV., La vida humana, origen y desarrollo, Reflexiones bioéticas de Científicos y Moralistas, FIUC. Universidad Pontificia Comillas, Barcelona: Madrid-Instituto Borja de Bioética.

- Dunphy, W. (1972). La nueva moral. Salamanca: Ed. Sígueme.

- Ferrer, J y Martínez J. (coord.) (2002). Bioética: un diálogo plural: homenaje a Javier Gafo Fernández. Universidad Pontificia de Comillas, Servicio de Publicaciones. España.

- Gafo, J. (Ed.). (1986-1998). Colección Dilemas éticos de la Medicina actual. Madrid: Publ. Univ. Pontificia Comillas.

- Gracia D. Principios y metodología de la Bioética: Quaderns Caps n. 19

- Hottois G. (2001). Biomedicina o Biotecnología aplicada al hombre? Colección Bíos y Éthos, Ediciones el Bosque, Bogotá, Vol. 22.

- Jonas, H. (1995). El principio de Responsabilidad. Ensayo de una ética para la civilización tecnológica. Barcelona: Editorial Herder.

- Lonergan, B. (1988). Pour une méthode en théologie. Traducción de Gerardo Remolina S.J. Salamanca: Ediciones Sígueme.

- Simón P. (2002). El consentimiento informado: Abriendo nuevas brechas. En problemas prácticos del consentimiento informado. Cuadernos de la Fundació Víctor Grífols i Lucas. No. 5. Barcelona.

- Masia, J. (2006). Tertulias bioéticas. Manejar la vida, cuidar a las personas. Madrid: Trotta.

- Roldán, S. (2001) Una propuesta bioética al debate sobre el aborto en Colombia, Pontificia Universidad Javeriana. Trabajo de Grado. Instituto de Bioética -CENALBE-. Bogotá. Capítulos I, III, IV.

- Roldán, S. (2010). Una reflexión desde la Teología moral a la hominización del embrión humano. Santiago de Chile/Madrid: FELAIBE y AEBI; e-book n 4592010. Web: www.aebioetica.org ó www.bioeticachile.cl/felaibe.

- Roldán, S. (2010). Bioética: Una hermenéutica para la dignidad humana. Simposio Internacional en Humanismo y Bioética. Bogotá: Fundación Santa Fe de Bogotá.

- Torralba, F. (1999). Los límites del principio de autonomía. Consideraciones filosóficas y bioéticas, en: Labor Hospitalaria, No. 251, pp. 19-32.

- Engelhardt, T. (1995). Los fundamentos de la Bioética. España, Ediciones Paidos,

- VIDAL M. (1990). Moral de actitudes, Volúmenes 1,2, Madrid,

- Zamudio, L. (2000). El aborto en Colombia: dinámica sociodemográfica y tensiones socioculturales. En: Revista Derecho Del Estado. Ed.: v. fasc. p. -, Colombia

- Zamudio, L. (1998). Aborto y salud pública en Colombia. En: Profamilia. Planificación, Población Y DesarroIlo. Bogotá: ed. Profamilia v.16 fasc. p.22 - 33. 